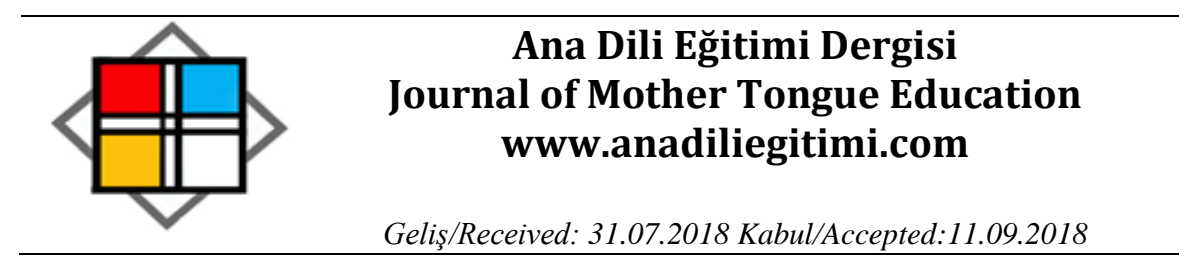

\title{
Yabancı Dil Olarak Türkçe Öğreten Öğretmenlerin Kültürlerarası Duyarlılığı*
}

\author{
Damla SAYGILI ** \\ Fatih KANA ${ }^{* * *}$
}

\begin{abstract}
Öz
Bu araştırmanın amacı, yabancı dil olarak Türkçe öğreten öğretmenlerin kültürlerarası duyarlılı̆ı̆ı belirlemektir. Bu amaç doğrultusunda araştırmada yabancı dil olarak Türkçe öğreten öğretmenlerin kültürlerarası duyarlıııla ilgili görüşlerinin; cinsiyet, hizmet içi eğitim alma, yabancı dil bilme, yurt dışında yaşama, çalışma yılı, eğitim durumu ve bilinen dil sayısı değişkenlerine göre istatiksel olarak anlamlı bir farklılık gösterip göstermediği araştırılmıştır. Araştırmada, karma çeşitleme deseni içerisinde yer alan "Tek Noktada Birleştirme Modeli" kullanılmışıı. Araştırmaya yönelik tamamlayıcı veriler toplamak veya aradaki farklılıkları ortaya koyarak daha güvenilir sonuçlar elde etmek amacıyla bu model seçilmiştir. Araştırmanın örneklemi çeşitli kurumlarda görev yapan, yabancı dil olarak Türkçe öğreten 133 öğretmenden oluşturmaktadır. Araştırmada, Chen ve Starosta (2000) tarafından geliştirilen "Kültürlerarası Duyarlılık Ölçeği" kullanılmıştır. Araştırmanın nicel verilerinin analizi SPSS 21.0 istatistik paket programından yararlanılarak yapılmıştır. Verilerin analizinde frekans, yüzde, aritmetik ortalama, $t$-testi, tek yönlü varyans analizi (ANOVA) gibi istatiksel tekniklerden yararlanılmıştır. Araştırmada nitel veriler, kodlamalar ve temalar aracılı̆ı̀la anlamlı hale getirilerek nitel verilerin çözümlenmesinde içerik analizi uygulanmıştır. Araştırmada uygulanan "Kültürlerarası Duyarlılık Ölçeği"ne göre yabancı dil olarak Türkçe öğreten öğretmenlerin kültürlerarası duyarlıık ve alt boyutları algı düzeylerinin yüksek olduğu belirlenmiştir. Öğretmen duyarlılığının en yüksek olduğu alt boyut kültürlerarası etkileşimde katılım, en düşük olduğu alt boyut ise kültürlerarası etkileşimde özendir. Öğretmenlerin görüşlerinin; cinsiyet, hizmet içi eğitim alma, yabancı dil bilme, yurt dışında yaşama, çalışma yılı, eğitim durumu, bilinen dil sayısı değişkenlerine göre istatiksel olarak anlamlı bir farklılık göstermediği belirlenmiştir. Araştırmanın nitel verilerine göre öğretmen görüşlerinin "dil ve kültür bir bütündür", "dil kültürün taşıyıcısıdır" ifadelerinde yoğunlaştığı tespit edilmiştir. Bu bakımdan nitel veriler nicel bulguları desteklemektedir.
\end{abstract}

Anahtar Kelimeler: Kültür, kültürerarası duyarılık, yabancı dil olarak Türkçenin öğretimi

\section{Intercultural Sensitivity of the Turkish as a Foreign Language Teachers}

\begin{abstract}
The purpose of this study is to determine the levels of perceptions about the intercultural sensitivity and its sub-dimensions of the Turkish as a foreign language teachers and to reveal the opinions on the importance of culture in teaching Turkish as a foreign language. In line with this purpose, it is examined whether the opinions of the Turkish as a foreign language teachers show a statistically significant difference in terms of certain variables such as gender, receiving inservice training, knowing a second language, living abroad, tenure, degree, the number of foreign languages spoken. Furthermore in this study, the importance of culture in teaching Turkish as a
\end{abstract}

\footnotetext{
${ }^{*}$ Bu makale ikinci yazar danışmanlığında hazırlanan yüksek lisans tezinden üretilmiştir.

** Öğretmen, Milli Eğitim Bakanlığı, Çanakkale, damladogan.pin@gmail.com

*** Dr. Öğretim Üyesi, Çanakkale Onsekiz Mart Üniversitesi, Eğitim Fakültesi, Türkçe ve Sosyal Bilimler Eğitimi Bölümü, Çanakkale, fatihkana@hotmail.com
} 
foreign language has been examined. The study was performed with "Single Point Aggregation Model", which is a mixed variation design. The reason for the selection of such model was to collect complementary data for the study and to obtain more reliable results through the identification of the differences between them. The sample of the study consisted of a total of 133 Turkish as a foreign language teachers working in different institutions. The study employed "the Intercultural Sensitivity Scale" developed by Chen and Starosta (2000). The analysis of the quantitative data of the study was performed by means of SPSS 21.0 statistical analysis software program. The statistical methods such as frequency, percentage, arithmetic mean, t-test, one way analysis of variance (ANOVA) were applied in the analysis of the data. The qualitative data were transformed into codes and themes and a content analysis was conducted in the analysis of the qualitative data. The quantitative data of "the Intercultural Sensitivity Scale" in the study pointed out high levels of perceptions for the intercultural sensitivity and its sub-dimensions of the Turkish as a foreign language teachers. The sub-dimension on which the sensitivity of teachers was at the highest was participation in intercultural interaction while the sub-dimension where it was at the lowest was attention to intercultural interaction. The study concluded that the opinions of the Turkish as a foreign language teachers did not show a statistically significant difference in terms of gender, receiving in-service training, knowing a second language, living abroad, tenure, degree, the number of foreign languages spoken. According to the qualitative data of the study, most of the teachers implied that language and culture together form a whole and that language serves as a culture carrier. In this regard, the qualitative data supported the quantitative findings.

Keywords: Culture, intercultural sensitivity, teaching Turkish as a foreign language

\section{Giriş}

Duygu, düşünce ve isteklerin aktarıldığı bir araç olan dil, insanoğlunun en temel gereksinimlerindendir. Dil, bu gereksinimler sonucunda çeşitli işlevler üstlenerek gelişimini sürdürmektedir. Tarihsel gelişimi içerisinde araştırmacılar dilin tanımı, işlevi, yapısı ile ilgili çeşitli görüşler ortaya atmışlardır. “Dil, bir toplumdaki ortak ögeler ve kurallardan yararlanarak başkalarına aktarılmasını sağlayan çok yönlü bir dizge olarak ifade edilmektedir (Aksan, 2009, s. 55)." Dil sayesinde bir birlik oluşur ve bu bir birlik milleti meydana getirir (Kaplan, 2006, s. 39). Dil, medeniyetlerin inşa edilmesinde doğrudan etkili olmuş, mükemmel bir anlatma aracıdır (Banguoğlu, 2011, s. 9-10). Dil; kültürü oluşturan ve geliştiren, nesilden nesile aktaran, kültürün farklı coğrafyalara yayılmasını sağlayan doğal bir araçtır (Uygur, 2000, s. 19-20). Bu yüzden dil öğretimi aynı zamanda kültür öğretimini de beraberinde getirmektedir. Özellikle yabancı dil öğretimini kültür ögesinden bağımsız düşünmek dil ve kültür arasındaki doğal bağı göz ardı etmek demektir.

Kültür sözcüğü köken bakımından Latincedir ve "toprağı işleme" anlamına gelmektedir. Toprağı işleme belirli bir çaba gerektiren ve bu çabanın sonunda mahsulün alındığı aşamalı bir süreçtir. Kültür kavramı özelleşerek ilkel kültür, ileri kültür, beşerî kültür, teknik kültür, yerleşik kültür, aşiret kültürü, kültür kavimleri-tabiat kavimleri gibi çeşitli anlamlarda da kullanılmıştır (Kafesoğlu, 2010, s. 15). Insanoğlu tabiatı işlerken kendini de maddî ve manevî olarak işlemiştir. Tarlanın işlenmesiyle ürünler, duygu ve düşüncenin işlenmesi ile sanat ve felsefe ortaya çıkmıştır (Kaplan, 2006, s. 33). Kültürü insanlar eğitimle öğrenir, dil ve iletişim yoluyla kültürü sürdürür ve başka nesillere aktarır (Güvenç, 1997, s. 15). 
Dil, toplumda çeşitli işlevler üstlenmektedir. Dil, bir iletişim aracı olması yanında bir toplumun kültürünü taşıyan ortak bir hazinedir ve toplumun aynasıdır. Toplum ve kültürde var olan her şey dilde karşılığını bulur (Güvenç, 1997, s. 47).

Bir ulus, kendini o dilin sözcükleriyle ifade eder. Dildeki benzetmeler, aktarmalar, deyim ve atasözleri bir ulusun dünya görüşü yansıtmaktadır (Aksan, 2005, s. 58). Günümüzde gittikçe artan teknolojik gelişmeler iletişimin, kültürün ve dilin tanımını değiştirmekte; çok kültürlü bireylerin ortaya çıkmasını sağlamaktadır. Bilgi birikiminin, yeniliğin, yaratıcılığın, kültürel bilincin önem kazandığı bu dönemde yabancı dil öğretimini sadece geleneksel yöntemlerle sınırlamak mümkün değildir (Kramsch, 2014, s. 249). Bu bağlamda kültürlerarası iletişim yeterliliği yaklaşımı kültürel sınırların ortadan kalktığı günümüzde önem kazanmaktadır. Yabancı dil öğretimi kültürel ilişkilerin ve karşılıklı iletişimin en önemli ögelerinden birini oluşturmaktadır. Kültürlerarası bildirişim yoluyla ön yargıları ve yanlış anlaşılmaları ortadan kaldırmak, sağııkı bir iletişim kurmak mümkün olmaktadır. Bu bakımdan kültürlerarası iletişim yeterliliği yaklaşımı yabancı dil öğretimi sürecinde kültür öğrenimine ve aktarımına vurgu yapmaktadır. Bu süreçte dil ait olduğu kültürün özellikleri ile verilmekte, öğrencilerin öğrendikleri dilin kültürel özelliklerine ve kendi kültürlerine karşı farkındalık kazanmaları sağlanmaktadır (Pehlivan, 2007, s. 17).

"Bir dili kullanabilmek demek, yalnızca yapıları ezberlemek anlamına gelmez, bu yapıların hangi durumlarda ve nasıl kullanılacağının da bilinmesi gerekmektedir" (Dilidüzgün, 2010, s. 13). Bu bakımdan yabancı dil derslerinde kültür aktarımı yapılırken ders içeriklerinin günlük yaşama uygun seçilmesi, öğrencilerin gereksinimleri doğrultusunda hazırlanması kültür aktarımına yeni bir boyut kazandırmıştır. Öğrenci kendi kültüründen yola çıkarak etkileşime girdiği yabancı dili anlamlandırmaya çalışmakta, yabancı kültürle bir çeşit diyaloğa girmektedir (Tapan, 1990, s. 57).

Kültürlerarası duyarlılık, bir bireyin kültürlerarası iletişimde kültürel farklılıkları tanıma, öğrenme ve kültürel farklılıklara saygı duyma konusundaki duygusal kapasitesini ifade etmektedir (Chen ve Starosta, 2000, s. 353-383). Hammer ve arkadaşları (2003, s. 422) kültürlerarası duyarlılık kavramını, kültürel farklııkları ayırt etme ve deneyimleme becerisi olarak tanımlamaktadırlar. Bhawuk ve Brislin (1992, s. 414) kültürlerarası duyarlılığı; kültürel farklııklara ve farklı kültürlerden insanların bakış açılarına karşı duyarlı olmak şeklinde ifade etmektedirler. Genel olarak kültürlerarası duyarlıık bireylerin farklı kültürlere ve farklı kültürlerden bireylerin görüşlerine saygı duyması, değer vermesi olarak tanımlanabilmektedir.

Yabancı dil olarak Türkçenin öğretiminde çeşitli unsurlar ön plana çıkmaktadır. Bu unsurlardan biri de kültür kavramıdır. Dil öğretimi, kültür öğretimini de beraberinde getiren bir süreçtir. Bu durumun oluşmasında dilin kültür aktarıcısı olma işlevi önemli rol oynamaktadır. Toplum 
ve kültürde var olan her şey dilde ifadesini bulur. Kültürün gelişmesi ile dil, dilin gelişmesi ile kültür gelişir (Güvenç, 1997, s. 48). Bu bağlamda dil öğretimini sadece dil bilgisi ile sınırlamak değişen, yenilenen ve ülke sınırlarının ortadan kalktığı 21. yüzyılda işlevsiz bir yaklaşım haline gelmektedir. Kültürlerarası iletişim yeterliliği yaklaşımı bu noktada öğretim sürecine farklı bir bakış açısı getirmektedir. Bu yaklaşımla bireyler farklı kültürlerle çatışma yaşamadan iletişim kurabilmekte ve kendi kültürlerinin sınırlarından çıkarak yeni kültürlere adım atmaktadırlar.

Öğretmenler, eğitim sürecinde öğrencilere akademik ve sosyal davranışlar kazandırmalarının yanında öğrenme ortamından da sorumludurlar. Özellikle öğretmenlerin öğrenme ortamını demokratik, eşitlikçi, farklııklara saygı duyan bir çerçevede düzenlemeleri gerekmektedir (Ünlü ve Örten, 2013, s. 289). Bu nedenle öğrencilerinin kültürel farklılıklarının bilincinde olan, kültürel duyarlılığa sahip öğretmenler eğitim sürecinde önem taşımaktadır (Rengi, 2014, s. 46). Öğretmenlerin; farklı sosyokültürel arka planlardan gelen öğrenciler, veliler ve diğer meslektaşları ile yüz yüze iletişimde olumlu yönde iletişimi başlatmaları ve sürdürmeleri gerekmektedir. Buna ek olarak sınıflarında ve okullarında açık görüşlülük ve saygının var olduğu bir iklim oluşturmaları eğitim sürecinin sağlıklı olması için önem taşımaktadır (Çiftçi, 2015, s. 60).

Öğretmenler, öğretim sürecinin en önemli halkalarından birini oluşturmaktadır. Özellikle yabancı dil öğretmenlerinin bu süreçte farklı sorumlulukları bulunmaktadır. Kendi kültürünü yansıtabilen, kültürüne yönelik unsurları ders işlenişinde etkili bir şekilde kullanabilen bir öğretmen; dil öğretim sürecini olumlu yönde etkileyecek ve öğrenmenin kalıcılığının artmasını sağlayacaktır. Bunun yanında öğretmenin öğrencilerinin kültürüne duyarlı olması ve onların kültürüne karşı olumlu tutum geliştirmesi öğretim sürecinin destekleyen diğer unsurlardandır.

Yabancı Dil Olarak Türkçenin Öğretimi alanında yapılan çalışmalarda kültür ögesinin genellikle öğrenen ve materyal odaklı incelendiği görülmüş, yabancı dil olarak Türkçe öğreten öğretmenler açısından yapılan çalışmaların sınırlı olduğu belirlenmiştir. Öğretmenlerin kültürlerarası duyarılı̆ğa sahip olması yabancı dil öğretiminde yadsınamayacak bir role sahiptir. Öğretmenler; farklı kültürlere karşı açık olmalı, gerekli duyarlılığı göstermeli ve kendi kültürlerini yansıtma konusunda rol model olmalıdırlar.

\section{Yöntem}

Bu bölümünde; kullanılan araştırma modeli, araştırma evreni ve örneklemi, araştırmada kullanılan veri toplama araçları, veri analiz teknikleri hakkında bilgi verilmiştir.

\section{Araştırma Modeli}

Yabancı dil olarak Türkçe öğreten öğretmenlerin kültürlerarası duyarlılığını belirlemeyi amaçlayan bu araştırmada Karma Çeşitleme Deseni içerisinde yer alan Tek Noktada Birleştirme 
modeli kullanılmıştır. Karma araştırmalar, nitel ve nicel araştırma desenlerinin bir arada kullanıldığı araştırma yöntemidir (Büyüköztürk, Çakmak, Akgün, Demirel, 2012, s. 234). Karma çeşitleme, karma araştırma desenleri içerisinde en çok kullanılan desendir. Bu desende araştırmacı nicel verilerle, nitel verileri karşılaştırma şansı yakalar ve bu desen, araştırmacının verilerini genişletmek istediğinde kullanabildiği en iyi desendir (Creswell ve Plano Clark, 2007, s. 63). Bu araştırmanın nicel bölümünü ankete dayalı veriler oluşturmaktadır (Büyüköztürk vd., 2012, s. 238). Araştırmanın nitel boyutunu ise öğretmenlerin konuyla ilgili görüşlerinin belirlenmeye çalışılması amacıyla ankete eklenen "Sizce yabancı dil olarak Türkçenin öğretiminde kültürün önemi nedir?” açık uçlu sorusu oluşturmaktadır.

\section{Evren ve Örneklem}

Karma araştırma modeliyle yapılan bu araştırmanın evrenini yabancı dil olarak Türkçe öğreten öğretmenler oluşturmaktadır. Araştırmada seçkisiz örnekleme yöntemlerinden basit seçkisiz örnekleme yöntemi kullanılmıştır. Basit seçkisiz örnekleme yönteminde her bir örneklemin aynı eşit ve bağımsız seçilme şansının bulunduğu örnekleme yöntemidir (Büyüköztürk vd., 2012). Araştırmaya katılan, yabancı dil olarak Türkçe öğreten 133 öğretmenin demografik özelliklerine ilişkin frekans dağılımları ise tablo $1^{\prime}$ de verilmiştir.

Tablo 1. Araştırmaya katılan öğretmenlerin cinsiyetleri

\begin{tabular}{ccc}
\hline Cinsiyet & $f$ & $\%$ \\
\hline Kadın & 76 & 57.1 \\
Erkek & 57 & 42.9 \\
Toplam & 133 & 100 \\
\hline
\end{tabular}

Tablo 1 incelendiğinde araştırmaya katılan yabancı dil olarak Türkçe öğreten öğretmenlerin \% 57'sinin kadın, \% 43'ünün erkek olduğu görülmektedir.

Tablo 2. Araştırmaya Katılan öğretmenlerin hizmet yılları

\begin{tabular}{ccc}
\hline Hizmet Yılı & $f$ & $\%$ \\
\hline $1-5$ yıl & 72 & 54.1 \\
$6-10$ yıl & 33 & 24.9 \\
$11-15$ yıl & 8 & 6 \\
16 ve üzeri yıl & 20 & 15 \\
\hline Toplam & 133 & 100.00 \\
\hline
\end{tabular}

Tablo 2 incelendiğinde araştırmaya katılan yabancı dil olarak Türkçe öğreten öğretmenlerin \% 54.1'inin 1-5 yıl, \% 24.9'unun 6-10 yıl, \% 6'sının 11-15 yıl, \% 15'inin 16 ve üzeri yıl hizmet yaptığı görülmektedir.

Tablo 3. Araştırmaya katılan öğretmenlerin eğitim durumları

\begin{tabular}{ccc}
\hline Eğitim Durumu & $f$ & $\%$ \\
\hline Lisans & 48 & 36.1 \\
Yüksek Lisans & 65 & 48.9 \\
Doktora & 20 & 15 \\
Toplam & 133 & 100.00 \\
\hline
\end{tabular}

Tablo 3 incelendiğinde araştırmaya katılan yabancı dil olarak Türkçe öğreten öğretmenlerin \% $36,1^{\prime}$ inin lisans, \%48.9'unun yüksek lisans, \%15'inin doktora mezunu olduğu görülmektedir. 
Tablo 4. Araştırmaya katılan öğretmenlerin yabancı dil olarak Türkçenin öğretimi ile ilgili hizmet içi eğitim alma durumları

\begin{tabular}{ccc}
\hline Hizmet İçi Eğitim & $f$ & $\%$ \\
\hline Evet & 96 & 72.2 \\
Hayır & 37 & 27.8 \\
\hline Toplam & 133 & 100.00 \\
\hline
\end{tabular}

Tablo 4 incelendiğinde araştırmaya katılan öğretmenlerin \%72.2'si Yabancı Dil Olarak Türkçenin Öğretimi ile ilgili hizmet içi eğitim aldığını belirtirken, $\% 27.8^{\prime} i$ ise Yabancı Dil Olarak Türkçenin Öğretimi ile ilgili hizmet içi eğitim almadığını belirtmiştir.

\section{Veri Toplama Araçları}

Bu araştırmada, veri toplama aracı olarak Chen ve Starosta (2000) tarafından geliştirilen "Kültürlerarası Duyarlılık Ölçeği" kullanılmıştır. 24 maddeden oluşan ölçek uzman görüşü dikkate alınarak Türkçeye uyarlanmıştır.

Araştırmada kullanılan ölçme aracı yabancı dil olarak Türkçe öğreten 133 öğretmene uygulanmıştır. Ölçekte yer alan maddelerin aynı özellikleri ölçüp ölçmediğini ve maddeler arasındaki ilişkiyi tespit etmek amacıyla yapılan açımlayıcı faktör analizi sonucuna göre ölçme aracında yer alan maddelerin 6 faktör altında toplandığı görülmüştür.

Öğretmenlerin, yabancı dil olarak Türkçe öğretiminde kültürün etkisi üzerine görüşlerini almak amacıyla ölçeğe, "Sizce yabancı dil olarak Türkçenin öğretiminde kültürün önemi nedir?" şeklinde açık uçlu bir soru eklenmiştir.

\section{Veri Analizi}

Araştırmada elde edilen verilerin analizi SPSS 21.00 istatistik paket programından yararlanılarak yapılmıştır. Verilerin analizinde frekans, yüzde, aritmetik ortalama, t-testi, tek yönlü varyans analizi gibi istatiksel teknikler kullanılmıştır. Araştırmada, Türkçe öğretmenlerinin ölçme aracında yer alan maddelere ne derecede katıldıklarını ortaya koymak amacıyla maddeler "kesinlikle katılmıyorum", "katılmıyorum", "kararsızım", "katılıyorum" ve "kesinlikle katılıyorum" biçiminde derecelendirilmiştir. Veri toplama aracında kullanılan beşli derecelendirme dört aralıktan oluşmasından dolayı 4/5 katsayısı dikkate alınarak ölçek puanlarının gerçek aralıkları bulunmuştur. Bu gerçek aralıklar şu şekildedir: 1-1.79 kesinlikle katılıyorum; 1.80-2.59 katılıyorum; 2.60-3.39 kararsızım; 3.40-4.19 katılmıyorum; 4.20-5.00 kesinlikle katılmıyorum. Araştırmanın nicel verileri analiz edilirken parametrik ve parametrik olmayan testlerin kullanılıp kullanılamayacağını belirlemek amacıyla veri dağııııının normalliğini incelemek amacıyla dağıımın normalliğine bakılmıştır.

Niceliksel verilerin karşılaştırımasında iki grup arasındaki farklııklarda t-testi, üç veya daha fazla bağımsız değişkenin olması halinde, birden fazla değişkenin ortalama 
puanlarının birbirinden anlamlı bir şekilde farklılaşıp farklılaşmadığının karşılaştırılmasında tek yönlü varyans (ANOVA) analizi yapılmaktadır. Araştırmada yabancı dil olarak Türkçe öğreten öğretmenlerin kültürlerarası duyarlıık puanlarının cinsiyet, hizmet içi eğitim alma, yabancı dil bilme, yurt dışında yaşama değişkenlerine göre karşılaştırılmasında bağımsız örneklem t-testi; hizmet yılı, eğitim durumu, bilinen dil sayısına göre anlamlı bir farklılık gösterip göstermediğinin karşılaştırılmasında tek yönlü varyans (ANOVA) yapılmıştır. Sonuçların yorumlanmasında 0.05 anlamlılık düzeyi ölçüt alınmıştır.

Yabancı dil olarak Türkçe öğreten öğretmenlerin demografik bilgilerine ilişkin bulgular frekans, aritmetik ortalama ve yüzde dağılımları ortak tablolar halinde düzenlenmiş ve yorumlanmıştır. Yabancı dil olarak Türkçe öğreten öğretmenlerin kültürlerarası duyarlılık düzeylerine ilişkin veriler analiz edilirken aritmetik ortalamalarından yararlanılmıştır.

Anketin sonuna eklenen "Sizce yabancı dil olarak Türkçenin öğretiminde kültürün önemi nedir?" şeklindeki açık uçlu soruya ilişkin olarak araştırmaya katılan 133 öğretmenden 126'sı anketin ilgili sorusuna yanıt vermiştir. Araştırmanın nitel bölümünde içerik analizi yöntemi kullanılmıştır. İçerik analizi, belirli kurallara dayalı kodlamalarla bir metnin bazı sözcüklerinin daha küçük içerik kategorileri ile özetlendiği sistematik, yinelenebilir bir teknik olarak ifade edilmektedir (Büyüköztürk, Çakmak, Akgün, Karadeniz, Demirel, 2012, s. 240). Veri analizinde genel olarak veriler anlamlı parçalara bölünür, kodlar geniş kategoriler veya temalar altında birleştirilerek karşılaştırmalar ve yorumlar yapılır (Creswell, 2013, s. 180). Bu araştırmada öğretmenlerin kültürel farklılık olarak algılamış oldukları unsurları belirlemeye yönelik açık uçlu sorunun verileri üzerinde temel kodlar belirlenmiş, ifadeler içerik benzerliği dikkate alınarak sınıflandırılmıştır. Ardından her bir sınıflandırmaya isimler verilerek ana temalara ulaşılmıştır. Veriler üzerinden elde edilen bulgular tablo ve yorumlar halinde verilmiştir; verileri daha çarpıcı hale getirmek için öğretmenlerin özgün ifadelerine de yer verilmiştir. Araştırmada yabancı dil olarak Türkçe öğreten öğretmenler Ö1, Ö2, Ö3, ... şeklinde kodlanmıştır.

\section{Geçerlilik ve Güvenilirlik}

Araştırmada veri toplama aracının yapı geçerliği açımlayıcı faktör analizi yoluyla gerçekleşmiştir. Veri toplama aracında güvenirlik maddelerin birbiriyle tutarlı görünüp görünmediğini analiz eder (Kalaycı, 2010). Araştırmada veri toplama aracının Cronbach Alfa katsayısı 0.72 olarak hesaplanmıştır. Kalaycı'ya (2010) göre 0.60 ve üzeri veri toplama aracının güvenilir olduğunu göstermektedir. Bu sonuca göre veri toplama aracının güvenilir olduğu söylenebilir. Araştırmada veri toplama aracının Kaiser-Meyer-Olkin (KMO) değeri 0.78; Barlett testi $\chi 2$ değeri ise 898.105 olarak hesaplanmıştır. Yapılan analizler sonucunda veri toplama aracının altı faktör olarak belirlendiği ve bu altı faktörün araştırmanın \%67.91'ini açıkladığı görülmektedir. 
Araştırmanın nitel bölümünde geçerliğin sağlanabilmesi için araştırmacının yansız olduğunu belirtmesi ve araştırma sürecinde göstermesi gerekmektedir. Araştırma sonunda ise araştırmanın genellenebilir olması önemlidir (Yıldırım ve Şimşek, 2011, s. 256). Araştırmacı, çalışmanın güvenirliğini artırmak için çalışma grubunun ifadeleri doğrudan alıntılarla desteklemiştir. Elde edilen bulgular genellenebilir ölçütlerle doğrulanmaya çalışımıştır. Araştırmanın güvenilirlik hesaplaması için Miles ve Huberman'ın (1994) önerdiği "Güvenirlik = Görüş Birliği / (Görüş Birliği + Görüş Ayrılığı)" güvenirlik formülü kullanılmıştır.

\section{Bulgular}

Araştırmanın bu bölümünde araştırma sürecinde kullanılan veri toplama aracından elde edilen veriler, nitel ve nicel bulgular olmak üzere ikiye ayrılmıştır. Karma çeşitleme deseninin doğasına uygun olarak öncelikle nicel verilerden sonrasında ise nitel verilerden elde edilen bulgulara yer verilecektir.

Yabancı Dil Olarak Türkçe Öğreten Öğretmenlerin Kültürlerarası Duyarlıık Üzerine Görüşleriyle Ilgili Nicel Bulgular ve Yorum

Araştırmanın bu bölümünde veri toplama aracının nicel kısmından elde edilen verilerden yararlanılacaktır.

Yabancı Dil Olarak Türkçe Öğreten Öğretmenlerin Kültürlerarası Duyarlılı ve Alt Boyutları Algı Düzeyleri

Araştırmaya katılan yabancı dil olarak Türkçe öğreten öğretmenlerin kültürlerarası duyarlılıkla ilgili görüşleri veri toplama aracından elde edilen ortalama puanlar doğrultusunda ortalamaları elde edilmiştir.

Tablo 5. Yabancı dil olarak Türkçe öğreten öğretmenlerin kültürlerarası duyarlıık ölçeğine ait görüşlerinin istatistiksel değerleri

\begin{tabular}{|c|c|c|c|c|}
\hline \multirow{9}{*}{-1} & & $\overline{\mathrm{x}}$ & Ss & \\
\hline & $\begin{array}{l}\text { 23. Sözlü veya sözsüz ifadeler aracılığıyla farklı kültürden meslektaşıma } \\
\text { anladığımı sıklıkla gösteririm. }\end{array}$ & 4.37 & 0.59 & \multirow{8}{*}{4.46} \\
\hline & 8. Farklı kültürlerden insanların değerlerine saygı duyarım. & 4.73 & 0.65 & \\
\hline & 13. Farklı kültürlerden insanlara karşı açık görüşlüyüm. & 4.50 & 0.67 & \\
\hline & 16. Farklı kültürlerden insanların davranış biçimlerine saygı duyarım. & 4.53 & 0.78 & \\
\hline & 24. Meslektaşlarımla aramda kültür farkı olmasından keyif alııım. & 4.08 & 0.87 & \\
\hline & 19. Farklı kültürden meslektaşlarımın hassasiyetlerine karşı duyarlıyım. & 4.58 & 0.74 & \\
\hline & $\begin{array}{l}\text { 17. Farklı kültürlerden insanlarla etkileşim halinde olduğumda mümkün } \\
\text { olduğunca bilgi elde etmeye çalışırım. }\end{array}$ & 4.49 & 0.67 & \\
\hline & $\begin{array}{l}\text { 21. Etkileşimimiz boyunca kültürel açıdan farklı meslektaşıma sıklıkla olumlu } \\
\text { tepkiler veririm. }\end{array}$ & 4.24 & 0.62 & \\
\hline \multirow{5}{*}{$\mathbf{n}$} & 3. Farklı kültürlerden insanlarla iletişim kurarken kendimden oldukça eminim. & 4.44 & 0.60 & \multirow{5}{*}{4.34} \\
\hline & 4. Farkıı kültürlerden insanların önünde konuşurken zorlanırım. & 4.24 & 0.88 & \\
\hline & $\begin{array}{l}\text { 5. Farklı kültürlerden insanlarla etkileşim kurduğumda ne söyleyeceğimi her } \\
\text { zaman bilirim. }\end{array}$ & 4.02 & 0.87 & \\
\hline & $\begin{array}{l}\text { 6. Farklı kültürlerden insanlarla etkileşim halinde olduğum zaman mümkün } \\
\text { olduğunca girişken olurum. }\end{array}$ & 4.20 & 0.71 & \\
\hline & 9. Farklı kültürlerden insanlarla etkileşim halinde olduğumda kolaylıkla huzursuz & 4.49 & 0.64 & \\
\hline
\end{tabular}


olurum.

10. Farklı kültürlerden insanlarla etkileşim halinde olduğumda kendimi güvende hissederim.

12. Farklı kültürlerden insanlarla birlikteyken sıklıkla cesaretim kırılır.

$4.39 \quad 0.84$

$4.44 \quad 0.63$

15. Farklı kültürlerden insanlarla etkileşim halindeyken kendimi sıklıkla yararsız hissederim.

\begin{tabular}{|c|c|c|c|c|}
\hline \multirow{2}{*}{ m } & 1. Farklı kültürlerden kişilerle etkileşimde bulunmaktan keyif alırım. & 4.78 & 0.55 & \multirow{2}{*}{4.71} \\
\hline & 18. Farklı kültürlerden insanların görüşlerini kabul etmem. & 4.64 & 0.49 & \\
\hline \multirow{2}{*}{$\theta$} & 7. Farklı kültürlerden insanlarla birlikte bulunmaktan hoşlanmam. & 4.63 & 0.64 & \multirow{2}{*}{3.99} \\
\hline & 20. Benim kültürümün diğerlerine göre daha iyi olduğunu düşünüyorum. & 3.36 & 1.20 & \\
\hline \multirow{2}{*}{ n } & 2. Diğer kültürlerden insanların dar görüşlü olduğunu düşünüyorum. & 4.39 & 0.88 & \multirow{2}{*}{4.26} \\
\hline & 22. Kültürel açıdan farklı insanlarla uğraşmam gereken durumlardan kaçınırım. & 4.14 & 0.88 & \\
\hline \multirow[t]{2}{*}{$\bullet$} & $\begin{array}{l}\text { 11. Farklı kültürlerden meslektaşlarıma karşı bir izlenim geliştirmeden önce } \\
\text { bekleme eğilimindeyim. }\end{array}$ & 3.68 & 1.00 & \multirow[t]{2}{*}{3.87} \\
\hline & 14. Farklı kültürlerden insanlarla etkileşim halindeyken çok dikkatliyimdir. & 4.07 & 0.85 & \\
\hline
\end{tabular}

Tablo 5 incelendiğinde genel olarak yabancı dil olarak Türkçe öğreten öğretmenlerin kültürlerarası duyarlılık algılarının $(\overline{\mathrm{x}}=4.34)$ yüksek olduğu görülmektedir. Araştırmaya katılan öğretmenlerin "Farklı kültürlerden kişilerle etkileşimde bulunmaktan keyif alırım." ( $\overline{\mathrm{x}}=4.78)$ maddesine en yüksek cevabı verdikleri görülmektedir. Öğretmenlerin farklı kültürlerden bireylerle tanışıp onlarla etkileşim kurmaya olumlu baktığı söylenebilir. Araştırmada en düşük ortalamaya sahip olan maddenin "Benim kültürümün diğerlerine göre daha iyi olduğunu düşünüyorum." ( $\bar{x}=3.36)$ maddesi belirlenmiştir.

Araştırmaya katılan öğretmenlerin kültürlerarası duyarlıık alt boyutlarına ilişkin algılarına ait aritmetik ortalamalar incelendiğinde kültürlerarası etkileşimde katılım $(\overline{\mathrm{x}}=4.71)$, kültürlerarası farklıııklara saygı ( $\bar{x}=4.46)$, kültürlerarası etkileşimde özgüven $(\overline{\mathrm{x}}=4.34)$, kültürlerarası etkileşimde ön yargı $(\overline{\mathrm{x}}=4.26)$, kültürlerarası etkileşimde öznellik ( $\overline{\mathrm{x}}=3.99)$, kültürlerarası etkileşimde özen $(\overline{\mathrm{x}}=3.87)$ alt boyutlarıyla ilgili sıralamanın oluştuğu görülecektir.

Cinsiyet Değişkeninin Yabancı Dil Olarak Türkçe Öğreten Öğretmenlerin Kültürlerarası Duyarlıık ve Alt Boyutlarına Ilişskin Algı Düzeylerine Etkisi

Cinsiyet değişkenin, yabancı dil olarak Türkçe öğreten öğretmenlerin kültürlerarası duyarlııı ve alt boyutlarına (kültürel farklılıklara saygı, kültürlerarası etkileşimde özgüven, kültürlerarası etkileşimde katıım, kültürlerarası etkileşimde öznellik, kültürlerarası etkileşimde ön yargı, kültürlerarası etkileşimde özen) etkisini test etmek için yapılan t-testi sonuçları tablo $12^{\prime}$ de verilmiştir.

Tablo 6. Yabancı dil olarak Türkçe öğreten öğretmenlerin cinsiyet değişkenine göre kültürlerarası duyarlıık ve alt boyutlarına ilişkin t-testi sonuçları

\begin{tabular}{cccccccc}
\hline Boyutlar & Cinsiyet & $\mathrm{N}$ & $\overline{\mathrm{x}}$ & $\mathrm{ss}$ & $\mathrm{sd}$ & $\mathrm{t}$ & $\mathrm{p}$ \\
\hline \multirow{2}{*}{ Kültürlerarası Farklılıklara Saygı } & Kadın & 76 & 4.54 & .39 & 131 & 2.83 & .00 \\
& Erkek & 57 & 4.30 & .59 & & & \\
Kültürlerarası Etkileşimde Katılım & Kadın & 76 & 4.80 & .31 & 131 & 3.02 & .00 \\
& Erkek & 57 & 4.58 & .50 & & & \\
Kültürlerarası Etkileşimde Özgüven & Kadın & 76 & 4.33 & .51 & 131 & 1.54 & .12 \\
& Erkek & 57 & 4.20 & .45 & & &
\end{tabular}




\begin{tabular}{cccccccc} 
& Kadın & 76 & 4.07 & .72 & 131 & 1.38 & .16 \\
Kültürlerarası Etkileşimde Öznellik & Erkek & 57 & 3.89 & .73 & & & \\
& Kadın & 76 & 4.32 & .66 & 131 & 1.18 & .23 \\
Kültürlerarası Etkileşimde Ön Yargı & Erkek & 57 & 4.18 & .73 & & & \\
& Kadın & 76 & 3.84 & .75 & 131 & -0.49 & .62 \\
\cline { 2 - 2 } & Erkek & 57 & 3.91 & .71 & & &
\end{tabular}

Tablo 6 incelendiğinde yabancı dil olarak Türkçe öğreten öğretmenlerin kültürlerarası duyarıııkları ile ilgili görüşlerinin alındığı kültürlerarası etkileşimde özgüven $\left(t_{(131)}=1.54 ; p>.05\right)$, kültürlerarası etkileşimde öznellik ( $t_{(131)=1.38 ;} p>$.05), kültürlerarası etkileşimde ön yargı $(t(131)=1.18$; $\mathrm{p}>$.05), kültürlerarası etkileşimde özen $\left(\mathrm{t}_{(131)}=-0.49 ; \mathrm{p}>\right.$.05) faktörleriyle cinsiyet değişkeni arasında istatistiksel olarak anlamlı bir farklılığın olmadığı görülmektedir. Tablo 12 incelendiğinde yabancı dil olarak Türkçe öğreten öğretmenlerin kültürlerarası duyarlılıkları ile ilgili görüşlerinin alındığı kültürlerarası farklılıklara saygı $\left(\mathrm{t}_{(131}\right)=2.83 ; \mathrm{p}<.05$ ve kültürlerarası farklılıklara saygı $\left(\mathrm{t}_{(131}\right)=2.83 ; \mathrm{p}<$ .05) faktörleriyle cinsiyet değişkeni arasında istatistiksel olarak anlamlı bir farklılığın olduğu görülmektedir. Tablo incelendiğinde yabancı dil olarak Türkçe öğreten kadın öğretmenlerin "kültürlerarası farklılıklara saygı" faktöründeki görüşlerinin $(\bar{x}=4.54)$, erkeklere göre $(\bar{x}=4.30)$ farklılaştığı görülmektedir. Yabancı dil olarak Türkçe öğreten kadın öğretmenlerin "kültürlerarası etkileşimde katılım" faktöründeki görüşlerinin $(\bar{x}=4.80)$, erkeklere $(\bar{x}=4.58)$ göre farklılık gösterdiği görülmektedir.

Yabancı Dil Olarak Türkçe Öğreten Öğretmenlerin Hizmet Iç̧i Eğitim Alma Durumlarının Kültürlerarası Duyarlılık ve Alt Boyutlarına iliş̧in Algı Düzeylerine Etkisi

Tablo 7. Yabancı dil olarak Türkçe öğreten öğretmenlerin hizmet içi eğitim alma durumlarına göre kültürlerarası duyarlılı ve alt boyutlarına ilişkin t-testi sonuçları

\begin{tabular}{cccccccc}
\hline Boyut & Hizmet içi Eğitim & $\mathrm{N}$ & $\overline{\mathrm{x}}$ & $\mathrm{Ss}$ & $\mathrm{sd}$ & $\mathrm{t}$ & $\mathrm{p}$ \\
\hline \multirow{2}{*}{ Kültürel Farklılıklara Saygı } & Evet & 96 & 4.49 & .51 & 131 & 2.05 & .04 \\
& Hayır & 37 & 4.29 & .44 & & & \\
Kültürlerarası Etkileşimde Katılım & Evet & 96 & 4.72 & .44 & 131 & 0.82 & .41 \\
& Hayır & 37 & 4.66 & .35 & & & \\
Kültürlerarası Etkileşimde Özgüven & Evet & 96 & 4.38 & .44 & 131 & 4.32 & .00 \\
& Hayır & 37 & 4.00 & .51 & & & .76 \\
Kültürlerarası Etkileşimde Öznellik & Evet & 96 & 3.98 & .76 & 131 & -0.29 & .76 \\
& Hayır & 37 & 4.02 & .65 & & & \\
Kültürlerarası Etkileşimde Ön yargı & Evet & 96 & 4.26 & .75 & 131 & -0.03 & .97 \\
& Hayır & 37 & 4.27 & .52 & & & \\
Kültürlerarası Etkileşimde Özen & Evet & 96 & 3.91 & .76 & 131 & -1.00 & .31 \\
& Hayır & 37 & 3.77 & .64 & & & \\
\hline
\end{tabular}

Tablo 7 incelendiğinde yabancı dil olarak Türkçe öğreten öğretmenlerin kültürlerarası duyarlııkları ile ilgili görüşlerinin alındığı kültürlerarası etkileşimde katılım $\left(\mathrm{t}_{(131)}=0.82 ; \mathrm{p}>.05\right)$, kültürlerarası etkileşimde öznellik $\left(t_{(131)}=-0.29 ; p>.05\right)$, kültürlerarası etkileşimde ön yargı $\left(t_{(131)}=-\right.$ 0.03; $p>.05)$, kültürlerarası etkileşimde özen $\left(t_{(131)}=-1.00 ; p>.05\right)$ faktörleriyle Yabancı Dil Olarak Türkçenin Öğretimi alanında hizmet içi eğitim alma durumları arasında istatistiksel olarak anlamlı bir farklıı̆ıın olmadığı görülmektedir. Tablo incelendiğinde hizmet içi eğitim alan öğretmenlerin 
"kültürlerarası farklılıklara saygı" faktöründeki görüşlerinin $(\overline{\mathrm{x}}=4.49)$ hizmet içi eğitim almayan öğretmenlere göre $(\bar{x}=4.20)$ farklılaştığı görülmektedir. Hizmet içi eğitim alan öğretmenlerin hizmet içi eğitim almayan öğretmenlere göre farklı kültürlerden insanlara karşı açık görüşlü oldukları ve onların değerlerine saygı duydukları söylenebilir. "Kültürlerarası etkileşimde özgüven" faktöründe hizmet içi eğitim alan öğretmenlerin görüşleri $(\bar{x}=4.38)$ hizmet içi eğitim almayan öğretmelerin $(\bar{x}=$ 4.00) görüşlerine göre farklılık göstermektedir. Kültürlerarası duyarlılığın alt boyutu olan kültürlerarası etkileşimde özgüvenin hizmet içi eğitim alan öğretmenlerin lehine değiştiği görülmektedir. Hizmet içi eğitim alan öğretmenlerin hizmet içi eğitim almayan öğretmenlere göre farklı kültürlerden insanlarla etkileşim kurarken kendinden daha emin olduğu, kendine güvendiği ileri sürülebilir.

Yabancı Dil Olarak Türkçe Öğreten Öğretmenlerin Yabancı Dil Bilme Durumlarının Kültürlerarası Duyarlıık ve Alt Boyutlarına Ilişskin Algı Düzeylerine Etkisi

Tablo 8. Yabancı dil olarak Türkçe öğreten öğretmenlerin yabancı dil bilme durumlarına göre kültürlerarası duyarlılı ve alt boyutlarına ilişkin t-testi sonuçları

\begin{tabular}{cccccccc}
\hline Boyut & Yabancı Dil Bilme & $\mathrm{N}$ & $\overline{\mathrm{x}}$ & $\mathrm{ss}$ & $\mathrm{Sd}$ & $\mathrm{t}$ & $\mathrm{p}$ \\
\hline Kültürel Farklılıklara Saygı & Evet & 112 & 4.43 & 0.52 & 131 & -0.12 & 0.90 \\
& Hayır & 21 & 4.45 & 0.40 & & & \\
Kültürlerarası Etkileşimde Katılım & Evet & 112 & 4.73 & 0.41 & 131 & 1.38 & 0.17 \\
& Hayır & 21 & 4.59 & 0.40 & & & \\
Kültürlerarası Etkileşimde Özgüven & Evet & 112 & 4.32 & 0.47 & 131 & 2.52 & 0.01 \\
& Hayır & 21 & 4.03 & 0.55 & & & \\
Kültürlerarası Etkileşimde Öznellik & Evet & 112 & 4.05 & 0.74 & 131 & 2.10 & 0.03 \\
& Hayır & 21 & 3.69 & 0.60 & & & \\
Kültürlerarası Etkileşimde Ön yargı & Evet & 112 & 4.26 & 0.69 & 131 & -0.13 & 0.89 \\
& Hayır & 21 & 4.28 & 0.73 & & & \\
Kültürlerarası Etkileşimde Özen & Evet & 112 & 3.84 & 0.75 & 131 & -1.00 & 0.31 \\
& Hayır & 21 & 4.02 & 0.62 & & & \\
\hline
\end{tabular}

Tablo 8 incelendiğinde yabancı dil olarak Türkçe öğreten öğretmenlerin kültürlerarası duyarlııkları ile ilgili görüşlerinin alındığı kültürlerarası farklııklara saygı $\left(t_{(131)}=-0.12 ; p>.05\right)$, kültürlerarası etkileşimde katılım $\left(t_{(131)}=1.38 ; p>.05\right)$, kültürlerarası etkileşimde ön yargı $\left(t_{(131)}=-0.13\right.$; $p>.05)$, kültürlerarası etkileşimde özen $\left(t_{(131)}=-1.00 ; p>.05\right)$ faktörleriyle yabancı dil bilme durumları arasında istatistiksel olarak anlamlı bir farklılığın olmadığı görülmektedir. "Kültürlerarası etkileşimde özgüven" faktöründe hizmet içi eğitim alan öğretmenlerin görüşleri $(\bar{x}=4.38)$ hizmet içi eğitim almayan öğretmelerin $(\bar{x}=4.00)$ görüşlerine göre farklılık göstermektedir. Kültürlerarası duyarlılığın alt boyutu olan kültürlerarası etkileşimde özgüvenin hizmet içi eğitim alan öğretmenlerin lehine değiştiği görülmektedir. Hizmet içi eğitim alan öğretmenlerin hizmet içi eğitim almayan öğretmenlere göre farklı kültürlerden insanlarla etkileşim kurarken kendinden daha emin olduğu, kendine güvendiği ileri sürülebilir. Hizmet içi eğitim alan öğretmenlerin "kültürlerarası etkileşimde öznellik" düzeyinin $(\bar{x}=3.98)$ hizmet içi eğitim almayan öğretmenlere $(\bar{x}=4.02)$ göre daha yüksek düzeyde olduğu düşünülebilir. 
Yabancı Dil Olarak Türkçe Öğreten Öğretmenlerin Türkçe Öğretiminde Kültürün Önemine Illişkin Algıları

Anketin sonuna eklenen "Sizce yabancı dil olarak Türkçenin öğretiminde kültürün önemi nedir?" şeklindeki açık uçlu soruya ilişkin olarak araştırmaya katılan 133 öğretmenden 126'sı anketin ilgili sorusuna yanıt vermiştir. Verilen yanıtlar üzerinden "Dil öğretimi kültür aktarımıdır.", "Dil öğretimi kültürden bağımsız düşünülemez.", "Kültür, dil öğretim sürecini olumlu yönde geliştirir.”, "Kültür öğretimi değerler eğitimi açısından önemlidir.", "Kültür öğretimi dünyaya bakış açısını geliştirir.", "Kültür, öğretimi iletişim kurma bakımından önemlidir." olmak üzere altı temaya ulaşıımıştır. Öğretmenlerin verdiği cevaplar üzerinden temalara ilişkin frekans ve yüzde dağılımları Tablo 9'da verilmiştir.

Tablo 9. Yabancı dil olarak Türkçe öğreten öğretmenlerin Türkçe öğretiminde kültürün önemine ilişkin görüşlerinin frekans ve yüzde dağııımı

\begin{tabular}{ccc}
\hline Temalar & $\mathrm{f}$ & $\%$ \\
\hline Dil ve kültür & 46 & 36.5 \\
Kültür ve öğretim süreci & 32 & 25.4 \\
Kültür aktarımı & 29 & 23.0 \\
Kültür ve iletişim & 8 & 6.3 \\
Değerler eğitim & 6 & 4.8 \\
Dünyaya bakış açısı & 5 & 4.0 \\
\hline Toplam & 126 & 100 \\
\hline
\end{tabular}

Tablo 9 incelendiğinde araştırmaya katılan yabancı dil olarak Türkçe öğreten öğretmenlerin 46'sı yabancı dil olarak Türkçe öğretiminde dil ve kültürün bir bütün olduğunu; araştırmaya katılan öğretmenlerden 32'si yabancı dil olarak Türkçe öğretiminde kültürün dil öğretim sürecini olumlu yönde geliştirdiğini; araştırmaya katılan öğretmenlerden 29'u yabancı dil olarak Türkçe öğretiminde dil öğretiminin kültür aktarımı olduğunu; araştırmaya katılan öğretmenlerden 8'i yabancı dil olarak Türkçe öğretiminde kültürün etkileşim kurma bakımından önemli olduğunu, araştırmaya katılan öğretmenlerden 6'sı yabancı dil olarak Türkçe öğretiminde kültürün değerler açısından önemli olduğunu, araştırmaya katılan öğretmenlerden 5 'i yabancı dil olarak Türkçe öğretiminde kültür öğretiminin bireylerin dünyaya bakış açısını geliştirdiğini ifade etmektedir.

"Dil ve kültür" teması ile ilgili yabancı dil olarak Türkçe öğreten öğretmenleri görüşleri şu şekildedir:

"Yabancı dil olarak Türkçe öğretiminde kültürün büyük bir önemi vardır. Dil, kültürün önemli bir yapı taşı olduğundan dil öğrenmek bir kültürü öğrenmek demektir; dil öğrenmek o toplumun yaşamını öğrenmek demektir. Yani dil öğretimi ve kültür birbirinden ayrı düşünülemez." (Ö14)

"Dil ve kültür birbirinden ayrılmaz iki olgu olduğu için yabancı bir dili öğretirken veya öğrenirken kültürün önemi yadsınamaz. Öğrenici ve öğretici hem kendi kültürünün farkına varır hem de hedef kültürden bir şeyler öğrenir." (Ö21) 
Yabancı Dil Olarak Türkçe Öğreten Öğretmenlerin Kültürlerarası Duyarlılığı

"Kültür aktarımı olmadan asla ve asla dil öğretilemez. Kültür aktarımı olmaksızın gerçekleştirilmeye çalışılan dil öğrenim çabaları keyifsiz ve anlamsızdır. Çünkü dil kültürel birikim oluşum kimlik ve mirastır. Her milletin dili kendi kültürünün aynasıdır." (Ö37)

"Dil öğretimi kültür öğretimini de beraberinde getirir. Bu ögeler birbirinden ayrı düşünülemez. Özellikle bir kişiye Türkçe öğretilirken onun kültürünün öğretici tarafından bilinmesi dil öğretimini kolaylaştırmakta ve çoğu zaman ön yargıları yıkmaktadır." (Ö39)

"Dil öğretmek sadece harfleri, kelimeleri ya da kavramları öğretmekten ibaret değildir. Dil ögrretiminin en önemli faktörü olan kültür aktarımını da sağlamaktır. Bir insan bir dili tamamen anlamak ve özümsemek istiyorsa o dilin kullanıcılarının kültürünü de öğrenmelidir." (Ö82)

"Yabancı dil öğretiminde kültürel değerlerin yabancıya aktarılıp o milletin özelliklerini yakından tanıma fırsatı verilmesi ayrı bir ehemmiyet taşımaktadır. Yabancı dil o milletin kültürel değerlerini tanımakla ancak öğrenilmiş sayılır. Dil ve kültür birbirinden ayrı düşünülemez." (Ö98)

"Kültür, bir milletin karakteridir. Bireyin düşünce yapısı ve davranış biçiminin yanı sıra ana dilinde de kültürün izlerini görebiliriz. Dil ve kültür kavramları iç içedir ve dahi kaynaşıktır. Karşımızdaki kişiyle sağlıklı iletişim kurabilmek ve yabancı dil öğretmek için dikkat edilmesi gereken belli başlı noktalardan biri de kültür kavramıdır. Atasözlerine, deyimlere, mecazlara ve kelime varlığına etki eden etmenlerin başında kültür bulunmaktadır." (Ö102)

"Kültür ve öğretim süreci" teması ile ilgili yabancı dil olarak Türkçe öğreten öğretmenleri görüşleri şu şekildedir:

"Kültür, bir insanın bünyesinde taşıdığı değerler bütünüdür. Yabancı dil öğretiminde kültürel aktivitelerin ve kültürel paylaşımların çok önemli olduğuna inanıyorum. Bu sebepten dolayı derslerimde Türk kültürü anlamında paylaşımlarda bulunuyorum. Ayrıca sadece derslerde de değil, hazırladığım sınav metinlerinde bile Türk kültürünü anlatan metinleri kullanıyorum. Yaklaşık 6 senedir bu alanda çalışıyorum ve öğrenciler hangi ülkeden olursa olsun kendi kültürlerinden bahsederken daha heyecanlı ve istekli olarak derse iştirak ettiklerini tecrübe ettim." (Ö6)

"Kültürel farklılıklar derslere renk katıyor. Kültürel ögeler tehlikeli sular olsa da karşılaştırmalarda herkes çok şey öğrenmekte. Kültürlerarasılık herkesin kişisel gelişimi açısından çok yararlı olmakta." (Ö14)

"Kültürün dil öğretimini kolaylaştırıcı bir etkisi vardır. Bu yüzden faydalanılmalıdır." (Ö23)

"Dilin daha iyi öğrenilebilmesi için kültürel özellikler de öğretilmelidir. Bir ülkenin kültürünü bilmek dilini daha kolay öğrenmeye olanak sağlar." (Ö35)

"Yabancı dil olarak Türkçe öğretiminde kültürlerarası etkileşimin ve sınıf içi farklı kültürlerden gelen öğrencilerin bir arada bulunmasının dil öğrenimini olumlu yönde etkilediğini hatta öğrenmeyi kolaylaştırdığı görüşündeyim." (Ö59) 
"Dil, kültürün önemli bir unsurudur. Dilimizdeki kelimelerin biz farkında olmasak da birer kültürel arka planı vardır. Örneğin "nazar değmesin" kelimesinin muadilini uzak doğu dillerinde bulmak zordur. Bu kelimenin kültürel arka planı bizim Orta Asya'dan Anadolu'ya getirdiğimiz inançlarda gizlidir. Kaynana, Kaynata kelimeleri de böyledir. Anne ve ata kelimelerinin "Kayın Ağacı" ile özdeşleştirilmesi bir tesadüf olmasa gerek. Dolasıyla Türk kültürünü ve Türk dilinin bu kültür içerisindeki komunu yeteri kadar kavrayamamış bir okutmanın nitelikli bir yabancı dil olarak Türkçe öğretmeni olması mümkün gözükmemektedir." (Ö79)

"Çok önemlidir. Çünkü dili öğretirken öğrettiğimiz insanlara ülkenin kültüründen bahsetmeliyiz. O kültürden örnekler vererek Türkçeyi daha iyi öğrenmesini sağlayabiliriz." (Ö95)

"Yabancı dil olarak Türkçe öğretiminde Türk kültürünün öneminden bahsedersek, tabii ki Türk kültürünün tanıtımı açısından ders sırasında kültürel bilgi aktarımı gerekir. Çok kültürlü bir sınıfta her bireyin kültürü ile Türk kültürünü karşılaştırarak Türk kültürü aktarılabilir. Kültürel bilgi içeren dersler, öğrenci ile Türk kültürü arasında bağlantı kurulması açısından önemlidir. Bu bağ kurulduktan sonra bazı Türkçe ifadeleri de anlamaları ve içselleştirmeleri daha kolay olacaktır." (Ö103)

"Kültür, bazı öğrencilerde dil öğretiminin amacıdır. Bu bağlamda kültürü sevdikleri veya merak ettikleri için dil öğrenenlere Türkçe öğretenler için çok önemli bir kaynaktır. Iyi değerlendirildiğinde süreci hızlandırır ve daha eğlenceli hale getirir." (Ö113)

"Kültür, yabancı dil olarak Türkçe öğretiminin temelini oluşturmaktadır. Öğrencilere ulaşabilmenin en kolay ve etkili yoludur. Öğrencilerin kültürleriyle hedef kültür arasında bağlantı kurarak dil öğretimini kolaylaştırmak mümkün hale gelmektedir." (Ö122)

“Kültür aktarımı” teması ile ilgili yabancı dil olarak Türkçe öğreten öğretmenleri görüşleri şu şekildedir:

"Toplumumuzun kültürel değerleri yabancı dil olarak Türkçe öğretiminde önemli bir yere sahiptir. Dil kültürün taşıyıcısıdır." (Ö3)

"Yabancı dil öğretimi aynı zamanda kültür aktarımıdır. Bu nedenle kendi kültürüne hâkim olmak çok önemlidir." (Ö10)

"Dil, kültür taşıyıcısı olma gibi bir özelliğe sahiptir. Dil öğretimi birebir kültürle alakalıdır. Öğretim esnasında dil asla gramatik yapıdan veya temel dil becerilerinden ibaret olarak görülmemeli; kültür aktarımı da göz önünde bulundurulmalıdır." (Ö40)

"Dil kültürün taşıyıcısıdır. Türkçeyi öğrenen bir insan doğal olarak Türk kültürünü de yakından tanıyacaktır." (Ö62)

"Dil sadece iletişimin değil aynı zamanda kültür aktarımının da aracıdır. Yeni bir dil öğrendiğimiz zaman sadece o dilde yapacağımı iletişimi değil aynı zamanda o dille üretilen dilsel üretimleri de öğrenmiş oluyoruz. Bu çok önemli bir şeydir. Sosyokültürel bilgi ve dil öğretilirken bu bilginin de en etkin şekilde aktarılması ve öğretilmesi gerekir.” (Ö69) 
Yabancı Dil Olarak Türkçe Öğreten Öğretmenlerin Kültürlerarası Duyarlılığı

"Dil öğretmek sadece harfleri, kelimeleri ya da kavramları öğretmekten ibaret değildir. Dil öğretiminin en önemli faktörü olan kültür aktarımını da sağlamaktır. Bir insan bir dili tamamen anlamak ve özümsemek istiyorsa o dilin kullanıcılarının kültürünü de öğrenmelidir." (Ö82)

"Dil Kültür taşıyıcısıdır. Bu sebeple kendi kültürünü bilmek ve aktarmakta başarılı olmak ne kadar önemli ise başka kültürleri tanımak ve onlara saygı duymak da bir o kadar önemlidir. Diğer kültürleri bildiğimiz ve saygı duyduğumuz kadar kendi kültürümüzün taşıyıcısı olabiliriz." (Ö105)

"Kültür, dil öğretiminde öğretilen dilin duvarlarını oluşturur. Dili öğrenen kapıyı açar ve bu duvarların arasında kendine uygun bir yer bulur." (Ö128)

"Kültür ve iletişim” teması ile ilgili yabancı dil olarak Türkçe öğreten öğretmenleri görüşleri şu şekildedir:

"Kültür; etkileşim ve iletişim kurma, bağ kurma açısından son derece önemlidir." (Ö22)

"Kültür, yabancı insanlarla iletişimiz açısından çok önemlidir." (Ö57)

"Kültür, zenginliktir ve iletişimi geliştirir. Insanların birbirini daha iyi anlamasına ve kendisini ifade etmesine yardımcı olur." (Ö15)

"Değerler eğitimi" teması ile ilgili yabancı dil olarak Türkçe öğreten öğretmenleri görüşleri şu şekildedir:

"Kültür öğretimi çok önemlidir ve özel günler, bayramlar gibi değerlerin öğretilmesi dışında kültüre özgü beden dili ve saygı kuralları gibi kavramlar da öğrencilere öğretilmelidir." (Ö12)

"Maddi ve manevi değerlerimizi anlatabilmemiz için önemlidir." (Ö61)

"Kültür, tutumları ve davranışları belirleyen temel unsurdur. Karşınızdaki milletin kültürünü bilmezseniz öğrencilerinizle tanışma adabından, derste vereceğiniz örneklere kadar yanlış uygulamalar yapabilirsiniz." (Ö96)

"Dünyaya bakış açısı" teması ile ilgili yabancı dil olarak Türkçe öğreten öğretmenleri görüşleri şu şekildedir:

"Kültür; farklı milletin yaşam şekillerini, dünya görüşlerini ve hayata karşı tutumlarını anlamamızı sağlayan bir araçtır." (Ö5)

"Farklı kültürleri görerek dünyaya bakış açımız değişiyor." (Ö7)

"Bir dili öğrenmek o dilde düşünmeyi öğrenmeyi gerektirir. Kültür, düşünce dünyasını var eden en önemli unsurlardan biridir. Bu açıdan bakıldığında Türkçeyi yabancı dil olarak öğreten birinin en önemli görevlerinden biri de Türk kültürünü doğru şekilde aktarmaktır. Bunun yanı sıra kültür aktarımı yapılırken dikkatli davranılmalı amacın empoze etmek değil öğrenciyi entegre etmek olduğu unutulmamalıdır. Kendi kültürümüzü aktarırken ortak bir kültürün aktarılmasına özen gösterilmeli, öznel algılardan kaçııılmalıdır. Türk kültürünün aktarımına öncelik verilmekle birlikte farklı kültürler hakkında da bilgi verilmesi, öğrencilerin kendi kültürleri hakkında konuşmaya teşvik edilmesi gerekmektedir. Bu öğretmenin kültürel bakışııı, ufkunu açacaktır.” (Ö25) 
Bulgular incelendiğinde araştırmaya katılan öğretmenlerin yabancı dil olarak Türkçe öğretiminde kültür ögesine önem verdikleri görülmektedir. Araştırmaya katılan öğretmenler ders işlenişinde, materyal seçiminde, konu dağılımında, öğrencilere karşı tavır ve tutumlarda kültür ögesine dikkat edilmesi gerektiğini ifade etmektedirler. Buna ek olarak öğrencinin kültürel özelliklerine karşı farkındalık geliştirilmesi gerektiğini belirtmektedirler.

\section{Tartışma, Sonuç ve Öneriler}

Araştırmanın bu bölümünde yabancı dil olarak Türkçe öğreten öğretmenlerin kültürlerarası hassasiyet düzeyleri ve bunlara etki eden değişkenlere bağlı bulgulara ve yabancı dil olarak Türkçenin öğretiminde kültürün önemine yönelik öğretmen görüşlerine ait bulgulara yer verilerek elde edilen sonuçlar tartışılacaktır. Araştırmanın sonunda bu konuda çalışma yapacak araştırmacılara öneriler sunulacaktır.

\section{Tartışma ve Sonuç}

Araştırmanın bu bölümünde araştırmanın problem cümlesinden ve alt problemlerinden elde edilen sonuçlar alanyazında yapılan çalışmalar ele alınarak tartışılııştır.

Araştırmanın Birinci Alt Problemine Ait Tartışma ve Sonuç. Araştırmaya katılan yabancı dil olarak Türkçe öğreten öğretmenlerin kültürlerarası duyarlııı ve alt boyutları (kültürel farklııklara saygı, kültürlerarası etkileşimde özgüven, kültürlerarası etkileşimde katılım, kültürlerarası etkileşimde öznellik, kültürlerarası etkileşimde ön yargı, kültürlerarası etkileşimde özen) algı düzeylerini belirlemek amacıyla yapılan analizler sonucunda ortaya çıkan bulgulara göre öğretmenlerin kültürlerarası duyarlılık düzeylerinin "yüksek" olduğu belirlenmiştir. Ölçek maddelerinin puan ortalamalarına bakıldığında "Farklı kültürlerden kişilerle etkileşimde bulunmaktan keyif alırım." ( =4.78) şeklinde ifade edilen 1. maddenin en yüksek ortalamaya sahip olduğu görülmektedir. Araştırmaya katılan yabancı dil olarak Türkçe öğreten öğretmenlerin farklı kültürlerden kişilerle bir arada bulunmaya, iletişim kurmaya olumlu baktıkları söylenebilir. Ölçek maddelerinde en düşük ortalamaya sahip olan maddenin ise "Benim kültürümün diğerlerine göre daha iyi olduğunu düşünüyorum." ( =3.36) şeklinde ifade edilen 20. madde olduğu görülmektedir.

Araştırmaya katılan öğretmenlerin kültürlerarası duyarlıık alt boyutlarına ilişkin algılarına ait aritmetik ortalamalar en yüksekten en düşüğe sıralandığında; kültürlerarası etkileşimde katılım ( =4.71), kültürlerarası farklıııklara saygı ( =4.46), kültürlerarası etkileşimde özgüven ( =4.34), kültürlerarası etkileşimde ön yargı ( =4.26), kültürlerarası etkileşimde öznellik (=3.99), kültürlerarası etkileşimde özen ( =3.87) olduğu görülmektedir. Bu durumda araştırmaya katılan öğretmenlerin farklı kültürlerden kişilerle iletişim kurmaktan keyif aldığı, farklı kültürlerden kişilerin değerlerine saygı duyduğu söylenebilir. 
Araştırma sonucunda yabancı dil olarak Türkçe öğreten öğretmenlerin kültürlerarası duyarlılıklarının yüksek olduğu belirlenmiştir. Bu sonuca paralel olarak Kalfa (2015, s. 249), çalışmasında yabancı dil olarak Türkçe öğreten öğretmenlerin Türkçeyi öğretirken aslında Türk kültürünü de öğrettiklerinin farkında olduğunu ifade etmiş, öğretmenlerin kültür ögesine önem verdiğini belirtmiştir. Mete ve Gürsoy (2013, s. 354) öğretmen yeterliliklerine ilişkin yaptıkları araştırmada öğretmenlerin meslekî tutum ve değerleri bölümünde en yüksek ortalamaya dil kültür etkileşimine duyarlı olabilme yeterliğinin sahip olduğunu ifade etmektedirler. Konuyla ilgili yapılmış çalışmalarda kültürün önemi ifade edilmiştir. Yabancı dil öğretiminden söz edildiğinde ilk akla gelen şey bir toplumun maddi ve manevi varlığı ile yazılı ve sözlü değerlerini oluşturan kültür kavramıdır (Demir ve Açık, 2014, s. 52). Bu bakımdan yabancı dil öğretimi kültür öğretimidir. Bireyler, ait oldukları toplumun ve o topluma ait kültürün kelime ve kavramlarıyla kendilerini ifade etmektedirler (Avcl, 2002, s. 2).

Araştırmanın íkinci Alt Problemine Ait Tartışma ve Sonuç. Araştırmaya katılan yabancı dil olarak Türkçe öğreten öğretmenlerin kültürlerarası duyarlılık ile ilgili görüşlerinin cinsiyet, hizmet içi eğitim alma, yabancı dil bilme durumlarına göre değişip değişmediğini belirlemek için yapılan analizler sonucunda yabancı dil olarak Türkçe öğreten öğretmenlerin kültürlerarası etkileşimde özgüven, kültürlerarası etkileşimde öznellik, kültürlerarası etkileşimde ön yargı, kültürlerarası etkileşimde özen alt boyutlarıyla cinsiyet değişkeni arasında istatistiksel olarak anlamlı bir farklılı̆ın olmadığı görülmektedir.

Kültürlerarası duyarlılığın alt boyutlarına ilişkin cinsiyet değişkeni incelendiğinde kültürlerarası farklııklara saygı, kültürlerarası etkileşimde katılım alt boyutlarında kadın öğretmenlerin puan ortalamalarının erkek öğretmenlere göre yüksek olduğu belirlenmiştir. Elde edilen bu sonuçlara göre kadın öğretmenlerin erkek öğretmenlere göre farklı kültürlerden kişilere daha saygılı ve daha fazla katılım sağladıkları söylenebilir. Yabancı Dil Olarak Türkçenin Öğretimi alanında öğretmenlerin kültürlerarası duyarlııı̆ını cinsiyet değişkenine göre inceleyen bir çalışma bulunmamaktadır. Üstün (2011, s. 84) öğretmen adayları üzerine yaptığı çalışmada kadın ve erkek öğretmenlerin kültürlerarası duyarılıı düzeyleri ile cinsiyet değişkeni arasında istatistiksel olarak anlamlı bir farklılık bulunmadığını belirtmiştir. Buna ek olarak kadın öğretmenlerin kültürlerarası duyarlılık düzeylerinin erkek öğretmenlerden yüksek olduğunu ifade etmiştir. Akın (2016, s. 40) yapmış olduğu çalışmada Türkçe öğretmeni adaylarının kültürlerarası duyarlılık puanlarının cinsiyet değişkenine göre anlamlı farklılık göstermediğini belirtmiştir.

Araştırmaya katılan yabancı dil olarak Türkçe öğreten öğretmenlerin kültürlerarası duyarlılık ile ilgili görüşlerinin hizmet içi eğitim alma durumlarına göre değişip değişmediğini belirlemek için yapılan analizler sonucunda yabancı dil olarak Türkçe öğreten öğretmenlerin kültürlerarası etkileşimde katılım, kültürlerarası etkileşimde öznellik, kültürlerarası etkileşimde ön yargı, 
kültürlerarası etkileşimde özen alt boyutlarıyla hizmet içi eğitim alma durumları arasında istatistiksel olarak anlamlı bir farklılığın olmadığı görülmektedir. Hizmet içi eğitim alan öğretmenlerin kültürlerarası farklılıklara saygı ve kültürlerarası etkileşimde özgüven alt boyutlarında hizmet içi eğitim almayan öğretmenlere göre puan ortalamalarının daha yüksek olduğu belirlenmiştir. Bu bakımdan hizmet içi eğitim alan öğretmenlerin hizmet içi eğitim almayan öğretmenlere göre farklı kültürlerden kişilerin değerlerine daha çok saygı duyduğu, farklı kültürlerden kişilerle iletişim kurarken kendine daha çok güvendiği söylenebilir. Kurudayıŏlu ve Sapmaz (2016, s. 101) çalışmalarında hizmet içi eğitimin önemini vurgulayarak görev yapan öğretmenlere yönelik hizmet içi eğitim programları düzenlenmesi ve öğretmen yeterliliklerinin arttırılması gerektiğini ifade etmişlerdir. Bu görüşe paralel olarak Mete ve Gürsoy (2013, s. 354) öğretmenlere gerekli desteğin sağlanıp sürekli bilgi alışverişinde bulunulması, Türkçenin yabancı dil olarak öğretildiği merkezler arasında iş birliği ve eşgüdümün sağlanması, hizmet öncesi ve hizmet içi eğitimlerle yurt içindeki ve yurt dışındaki öğretmenlerin sürekli gelişimlerinin desteklenmesi gerektiğini vurgulamıştır. Balcı ve Melanlıoğlu (2016, s. 1001) ana dili konuşuru olmayan öğretmenlere dikkat çekerek hizmet içi eğitimlerle öğretmenlerin desteklenmesinin öğretmen yeterliliklerini arttıracağını ifade etmişlerdir.

Araştırmaya katılan yabancı dil olarak Türkçe öğreten öğretmenlerin kültürlerarası duyarlılık ile ilgili görüşlerinin yabancı dil bilme durumlarına göre değişip değişmediğini belirlemek için yapılan analizler sonucunda yabancı dil olarak Türkçe öğreten öğretmenlerin kültürlerarası farklılıklara saygı, kültürlerarası etkileşimde katılım, kültürlerarası etkileşimde ön yargı, kültürlerarası etkileşimde özen alt boyutlarıyla yabancı dil bilme durumları arasında istatistiksel olarak anlamlı bir farklılı̆ın olmadığı görülmektedir. Yabancı bir dil bilen yabancı dil olarak Türkçe öğreten öğretmenlerin farklı kültürlerden kişilerle iletişim kurarken kendinden oldukça emin, mümkün olduğunca girişken oldukları ayrıca yabancı dil bilen öğretmenlerin daha öznel davrandıkları ileri sürülebilir. Mete (2012, s. 122) araştırmasında ulaştığı sonuçlara göre yabancı dil olarak Türkçe öğreten öğretmenlerin yabancı dil bilmesinin faydalı olduğunu belirtmiş, iletişim ve empati boyutuna dikkat çekmiştir. Kana, Boylu ve Başar yabancı dil olarak Türkçe öğretecek kişilerin Türkçe alan bilgisi ve öğretmenlik bilgisinin yanında mutlaka bir yabancı dil öğrenmeleri konusunda teşvik edilmeleri gerektiğini belirtmiştir (2016, s. 1136).

Araştırmanın Üçüncü Alt Problemine Ait Tartışma ve Sonuç. Araştırmanın bu bölümünde araştırmanın nitel bölümünü oluşturan "Sizce yabancı dil olarak Türkçenin öğretiminde kültürün önemi nedir?" sorusuyla ilgili elde edilen sonuçlara yer verilmiştir.

Araştırmaya katılan öğretmenlerin görüşlerine göre kültür ögesi yabancı dil olarak Türkçenin öğretiminde önem taşımaktadır. Öğretmen görüşlerinde üzerinde en çok durulan ifade $(n=46)$ dil ve kültürün bir bütün olduğudur. Mete (2012, s. 123) araştırmasında dil kültür ilişkisine bağlı olarak "Dil öğretimi aynı zamanda kültür öğretimidir." yaklaşımından hareketle öğretmenlerin sadece dil 
kurallarını bilmesinin yeterli olmayacağını, kültürel birikime de sahip olmaları gerektiğini ifade etmiştir (Kalfa, 2013, s. 97). Dil kültür ilişkisi göz önüne alındığında yabancı dil olarak Türkçe öğreten öğretmenlerin alan bilgisinin yanı sıra ulusal ve evrensel, kültürel değerleri de iyi bilen ve benimseyen öğretmenler olmaları önem taşımaktadır (Mete, 2012, s. 124). Yabancılara Türkçe öğretimi alanında çalışacak nitelikli bir öğretmenin yabancı dil öğretimine ilişkin teknik bilgiye, Türk diline ve kültürüne, öğretmenlik alan bilgisine sahip olması oldukça önemlidir (Kana, Boylu ve Başar, 2016, s. 1133).

Araştırmaya katılan öğretmenlerin bir kısmı (n=32) kültürün, dil öğretim sürecini olumlu yönde geliştirdiğini belirtmiştir. Derslerde Türk kültürüne yönelik unsurların kullanılmasının öğrencilerin derse karşı dikkatini arttığını, öğrenmeyi kolaylaştırdığını ifade etmişlerdir. Yabancı dil öğretiminde kültürel ögelerin aktarımı, öğrenme sürecini zevkli hale getirir (Kalfa, 2013, s. 167). Öğrenciler arasında bireysel farklııklar olsa da kültürel ortak paydalar öğrencileri birbirine yaklaştıracağından, ders kitaplarında dengeli oranlarda atasözleri ve deyimlerin kullanımına yer verilmesi önem taşımaktadır (Tüm, 2010, s. 677). Dil öğretiminde kültürel özelliklerin de verilmesi öğretimin başarıya ulaşılmasında önemlidir (Kalfa, 2013, s. 97).

Araştırmaya katılan öğretmenler dil öğretiminin kültür aktarımı $(n=29)$ olduğunu sıklıkla ifade etmişlerdir. Kalfa'nın (2013, s. 167) da belirttiği gibi dil hem kültürün önemli bir parçası hem de kültürün aktarıcısıdır. Karababa ve Canan (2009, s. 277) yabancı dil olarak Türkçe öğrenenlere Türk yazının tanıtılmasıyla Türkçe derslerinin, Türk kültürünü ve yaşamını yansıtan kültürlerarası bir köprüye dönüşeceğini ifade etmiştir. Dil öğretimi, hedef dille ilgili temel dil becerilerini kazandırmakla sınırlı değildir. Toplumda var olan tüm maddî ve manevî değerler dilde karşılığını bulur. Bu bakımından dil kültürün taşıyıcısıdır. Türkçeyi öğrenen bir kişi, doğal olarak Türk kültürünü de öğrenecektir. Bu nedenle yabancı dil olarak Türkçe öğreten öğretmenlerin, çağın gerektirdiği bilgi birikimine, geniş bir dünya görüşüne ve genel kültüre sahip olmaları gerekmektedir (Avcı, 2002, s. 2). Türk kültürünün yabancılara aktarımında en önemli unsurlardan biri öğretmenlerdir (Gün, Akkaya ve Kara, 2014, s. 4).

Araştırmaya katılan öğretmenler kültürün, etkileşim kurma bakımından önem taşıdığını ifade etmişlerdir. Kültürel farkındalık, farklı kültürlerden insanların arasında iletişimin gelişmesini sağlayarak insanların birbirini daha iyi anlamasına ve dolayısıyla daha iyi iletişim kurmasına yardımcı olmaktadır. Chen'in (1989, ss. 120-121) de belirttiği üzere bireylerin etkileşimde bulunduğu kişilerle empati kurması kültürlerarası iletişimde bulunması gereken özelliklerdendir. Kültürlerarası duyarlılığın arttırılmasıyla öğrencilerin diğer kültürlerden gelen bireylerle etkileşim kurması mümkün olmaktadır (Aksoy, 2016, s. 51).

Araştırmaya katılan öğretmenler kültür öğretiminin, değerler eğitimi açısından önemli olduğunu belirtmişlerdir. Kültür, tutum ve davranışları belirleyen temel unsurlardan biridir. Aşağıda verilmiş olan araştırma verilerinde yer alan örnek ifadeler bu durumu destekler niteliktedir: "Kültür, 
tutumları ve davranışları belirleyen temel unsurdur. Karşınızdaki milletin kültürünü bilmezseniz öğrencilerinizle tanışma adabından, derste vereceğiniz örneklere kadar yanlış uygulamalar yapabilirsiniz." "Kültür öğretimi çok önemlidir ve özel günler, bayramlar gibi değerlerin öğretilmesi dışında kültüre özgü beden dili ve saygı kuralları gibi kavramlar da öğrencilere öğretilmelidir."

Chen $(1989$, s. 121) kültürlerarası iletişim yeterliliğini dört boyutta ele almıştır. Bu boyutlardan biri kültürel bilinçtir. Kültürel bilince sahip bireyler o topluma ait sosyal kuralları, gelenekleri, değerleri ve toplumun işleyişine karşı olumlu tutum geliştirirler. Tapan'ın (1990, s. 55) da ifade ettiği gibi yabancı dil öğretimi amaç kültürden bağımsız düşünüldüğünde dilsel kullanımların öğrenci tarafından anlaşılması güçleşmektedir. Öğrencinin amaç dili öğrenmesi, o dili konuşan ülkenin kendine özgü değerler dizgesinin oluşturduğu toplumsal bağlam içinde dili doğru kullanmasıyla mümkün olacaktır. Tüm (2010, s. 676) bu görüşe paralel olarak bir topluma ait kültürün yansıması olarak ortaya çıkan atasözlerinin bağlama uygun kullanımının yabancı dil olarak Türkçe öğrenen öğrencilere öğretilmesinin öğrencilerin dilsel farkındalığını arttıracağını, değer ve inançları anlamasına yardımcı olacağını belirtmiştir. Bu bakımdan yabancı dil öğrenen kişi, dili öğrenirken aynı zamanda o dilin taşıdığı düşünce ve değerler dizgesini de öğrenir (Dilidüzgün, 1995, s. 12).

Araştırmaya katılan öğretmenler kültür öğretiminin, bireyin dünyaya bakış açısını geliştirdiğini ifade etmişlerdir. Mete ve Gürsoy $(2013$, s. 344) her dilin kendine has bir kültürel yapı ve bir dünya görüşü içerdiğini belirtmiştir. Yabancı olanı anlamak kişinin dünyaya bakış açısını, ufkunu genişletir (Ozil, 1991, s. 99). Yeni bir dil öğrenmeye başlayan bir öğrenci, sadece yeni bir dil değil aynı zamanda yeni bir kültür, yeni bir coğrafya ve yeni bir dünya ile tanışır (Güler, 2012, s. 131).

\section{Öneriler}

1. Araştırmadan elde edilen bulgulara göre yabancı dil olarak Türkçe öğreten öğretmenler dil öğretiminde kültürün önemini vurgulamış, dil ve kültürün bir bütün olduğunu ifade etmişlerdir. Öğretmenlerin ders işlenişinde kültürel unsurları kullanmalarına ve bu unsurları içeren ders materyalleri geliştirmelerine yönelik hizmet içi eğitimler düzenlenebilir.

2. Araştırma sonucuna göre yabancı dil olarak Türkçe öğreten öğretmenlerin mezun oldukları lisans bölümlerinin farklılık gösterdiği belirlenmiştir. Yabancı Dil Olarak Türkçenin Öğretimi alanında bir lisans programının açılması öğretmenlerin alandaki uzmanlığını ve yeterliliğini arttıracaktır.

3. Sınıf ortamı farkı kültürlerden gelen bireylere ve onların değerlerine açık olmalıdır. Demokratik bir sınıf ortamının oluşturulması kültürlerarası duyarlılı̆ının gelişmesini sağlayacaktır.

4. Kültürlerarası duyarlılığın arttırılması amacıyla Türk kültürünün özelliklerine yönelik tanıtım etkinlikleri yapılabilir. Yöresel kıyafetler, müzikler, yemekler gibi kültürel unsurları içeren etkinlikler aracılığıyla Türk kültürünün tanıtılması kültürlerarası bir köprü oluşturacaktır. 
5. Öğretim programlarının öğrenen ihtiyacına göre hazırlanması öğrencinin ders başarısını ve derse karşı motivasyonunu olumlu yönde etkilemektedir. Bu bakımdan tek tip bir öğretim program yerine meslek Türkçesine (C2 düzeyine) yönelik programlar hazırlanmalıdır.

6. Yabancı dil olarak Türkçe öğreten öğretmenlerin materyal paylaşmaları, içerik geliştirmeleri amacıyla web tabanlı bir eğitim portali geliştirilebilir. Geliştirilen bu portale öğrencilerin de erişmesi sağlanabilir.

7. Yabancı dil olarak Türkçe öğreten öğretmenlerin aynı zamanda bir kültür elçisi olduğu unutulmamalı; öğretmenlerin Türk kültürünü temsil kabiliyetine sahip olması gerekmektedir.

8. Yabancı dil olarak Türkçe öğreten öğretmenler; Türk kültürünün dünü, bugünü hakkında bilgi ve yarını hakkında fikir sahibi olmalıdırlar.

9. Yabancı dil olarak Türkçe öğreten öğretmenler ön yargılı olmamalıdırlar.

\section{Kaynaklar}

Akın, E. (2016). Türkçe öğretmen adaylarının kültürlerarası duyarlııklarının çeşitli değişkenler açısından incelenmesi (Siirt Üniversitesi örneği), Electronic Turkish Studies, 11(3), 29-42.

Aksan, D. (2005). Türkçenin gücü (9. baskı). Ankara: Bilgi Yayınevi.

Aksan, D. (2009). Her yönüyle dil: ana çizgileriyle dilbilim (5. baskı) Ankara: Türk Dil Kurumu Yayınları.

Avcı, Y. (2002). Türkçenin yabancı dil olarak öğretiminin kültür ve yöntem boyutu. Çanakkale Onsekiz Mart Üniversitesi I. Uluslararası Truva-Çanakkale Dil Eğitimi ve Okul Gelişimi Sempozyumu. Çanakkale, Türkiye.

Balıı, M. ve Melanlıoğlu, D. (2016). Ana dili konuşuru olmayan öğreticilerin görüşlerine göre yabancı dil olarak Türkçe öğretimi. Uluslararası Türkçe Edebiyat Kültür Eğitim (TEKE) Dergisi, 5(2). 986-1004.

Banguoğlu, T. (2011). Türkçenin grameri (9. baskı). Ankara: Türk Dil Kurumu Yayınları.

Bhawuk, D. P. ve Brislin, R. (1992). The measurement of intercultural sensitivity using the concepts of individualism and collectivism. International Journal of Intercultural Relations, 16(4), 413-436.

Büyüköztürk, Ş. (2002). Faktör analizi: temel kavramlar ve ölçek geliştirmede kullanımı. Kuram ve Uygulamada Eğitim Yönetimi, 32(32), 470-483.

Büyüköztürk, Ş., Çakmak, K. E., Akgün, Ö. E., Karadeniz, ş. ve Demirel, F. (2012). Bilimsel araştırma yöntemleri (13. baskı). Ankara: Pegem Akademi Yayınları.

Chen, G. M. (1989). Relationships of the dimensions of intercultural communication competence. Communication Quarterly, 37(2), 118-133.

Chen, G. M. ve Starosta, W. J. (2000). The Development and validation of the intercultural sensitivity scale. Human Communication, 3, 1-15.

Creswell, J. W. (2013). Nitel araştırma yöntemleri (Çev. Ed. M. Bütün, S. B. Demir). Ankara: Siyasal Kitabevi.

Creswell, J. W. ve Plano-Clark, V. L. (2007). Designing and conducting mixed methods research. London: Sage Publications.

Çiftçi, Acar, Y. (2015). Çokkültürlü eğitim bağlamında öğretmenlerin kültürel yeterliklerine ilişkin algıları. Doktora Tezi, Yıldız Teknik Üniversitesi, Sosyal Bilimler Enstitüsü, İstanbul.

Demir, A. ve Açık, D. (2014). Türkçenin yabancı dil olarak öğretiminde kültürlerarası yaklaşım ve seçilecek metinlerde bulunması gereken özellikler. Türklük Bilimi Araştırmaları, (30)30, 51-72. 
Dilidüzgün, Ş. (1995). Yabancı dil olarak Türkçe öğretiminde yazınsal metinler. Yüksek Lisans Tezi, İstanbul Üniversitesi Sosyal Bilimler Enstitüsü, İstanbul.

Dilidüzgün, Ş. (2010). Metindilbilim ve Türkçe Öğretimi. İstanbul: Morpa Yayınları

Güler, B. E. (2012). Yabancılara Türkçe Öğretiminde “Öğretmen” Unsuru. International Journal of Social Science, 5(2), 129-134.

Gün, M., Akkaya, A. ve Kara T. Ö. (2014). Yabancılara Türkçe Öğretimi Ders Kitaplarının Türkçe Öğretim Merkezlerinde Görev Yapan Öğretim Elemanları Açısından Değerlendirilmesi. Turkish Studies, 9(6), 1-16.

Güvenç, B. (1997). Kültürün abc'si (1. baskı) İstanbul: Yapı Kredi Yayınları.

Hammer, M. R., Bennett, M. J. ve Wiseman, R. (2003). Measuring Intercultural Sensitivity: The Intercultural Development Inventory. International Journal of Intercultural Relations, 27(4), 421-443.

Kafesoğlu, İ. (2010). Türk millî kültürü (29. baskı). İstanbul: Ötüken Yayınları.

Kalaycı Ş. (2010). SPSS uygulamalı çok değişkenli istatistik teknikleri. Ankara: Asil Yayıncılık.

Kalfa, M. (2013). Yabancılara Türkçe öğretiminde sözlü kültür unsurlarının kullanımı. Milli Folklor, 25(97), 167177.

Kalfa, M. (2015). Yabancı dil olarak Türkçe öğreten öğretmenlerin alan yeterliklerine dayalı gereksinim çözümlemesi. Eğitim ve Bilim, 40(181), 241-253.

Kana, F., Boylu, E. ve Başar, U. (2016). Yabancı dil olarak Türkçe öğretmeni yetiştirmenin gerekliliği ve lisans programı önerisi. Eğitimde Kuram ve Uygulama, 12(5), 1125-1138.

Kaplan, M. (2006). Kültür ve dil (21. baskı) İstanbul: Dergâh Yayınları.

Karababa, Z. C. ve Canan, Z. (2009). Yabancı dil olarak Türkçenin öğretimi ve karşılaşılan sorunlar. Ankara Üniversitesi Eğitim Bilimleri Fakültesi Dergisi, 42(2), 265-277.

Kramsch, C. (2014). The Challenge of globalization for the teaching of foreign languages and cultures. Electronic Journal of Foreign Language Teaching, 11(2), 11, 249-254.

Kurudayığlu, M. ve Sapmaz, S. (2016). Yabancı dil olarak Türkçe konuşma öğretimine dair öğretmen bilişleri. Journal of World of Turks/Zeitschrift für die Welt der Türken, 8(3), 85-102.

Mete, F. (2012). Yabancı dil olarak Türkçe öğretimine ilişkin öğretmen görüşlerinin değerlendirilmesi. Dede Korkut Türk Dili ve Edebiyatı Araştırmaları Dergisi, 1(1), 103-125.

Mete, F. ve Gürsoy, Ü. (2013). Yabancı dil olarak Türkçe öğretiminde öğretmen yeterliklerine ilişkin görüşler. Hacettepe Üniversitesi Eğitim Fakültesi Dergisi, 28(3), 343-356.

Miles, M. B. ve Huberman, A. M. (1994). Qualitative data analysis: An expanded sourcebook. (Second Edition). California: SAGE Publications.

Ozil, Ş., Baysal J., Ipşirolu, N. ve İpşiroğlu, Z. (1991). Çağdaş kültürümüz, olgular-sorunlar. İstanbul: Cem Yayınevi,

Pehlivan, F. (2007). Yabancı dil olarak Türkçe öğretiminde kültürlerarası etkileşim odaklı yaklaşım uyarınca metin çalışmaları. Yüksek Lisans Tezi, İstanbul Üniversitesi Sosyal Bilimler Enstitüsü, İstanbul.

Rengi, Ö. (2014). Sını öğretmenlerinin kültürel farklılık algıları ve kültürlerarası duyarlııkları. Yüksek Lisans Tezi, Kocaeli Üniversitesi Sosyal Bilimler Enstitüsü, Kocaeli.

Tapan, N. (1990). Yabancı dil olarak Almanca öğretiminde kültür bağlamının değerlendirilmesi, Alman Dili ve Edebiyatı Dergisi, 7, 55-68.

Tüm, G. (2010). Atasözlerinin değişik kültür ve dilleri anlamadaki rolü. Turkish Studies, 5(4), 663-678.

Uygur, N. (2000). Kültür kuramı (1. baskı). İstanbul: Yapı Kredi Yayınları. 
Ünlü, İ. ve Örten, H. (2013). Öğretmen Adaylarının Çokkültürlülük ve Çokkültürlü Eğitime Yönelik Algılarının İncelenmesi. Dicle Üniversitesi Ziya Gökalp Eğitim Fakültesi Dergisi, 21 (2013). 287-302

Üstün, E. (2011). Öğretmen adaylarının kültürlerarası duyarlılık ve etnikmerkezcilik düzeylerini etkileyen etmenler. Yüksek Lisans Tezi, Yıldız Teknik Üniversitesi Sosyal Bilimler Enstitüsü, İstanbul.

Yıldırım, A. ve Şimşek, H. (2011). Nitel araştırma yöntemleri (8. baskı). Ankara: Seçkin Yayıncılık.

\section{Extended Abstract Introduction}

Cross-cultural sensitivity refers to the emotional capacity of an individual to recognize cultural differences, learn about and respect them in a cross-cultural communication (Chen and Starosta, 2000, pp. 353383). The process of teaching Turkish as a foreign language includes various components one of which is culture. The process of language teaching leads to culture teaching because language is an important tool that functions as a culture carrier. Language includes all cultural and social features of a society. Culture and language improve each other alternately (Güvenç, 1997, s. 48). Teachers are one of the most important elements of this teaching process. Foreign language teachers particularly have various responsibilities in this process.

\section{Method}

In this chapter: the research model, population and sampling of the research, data collection tools used in the research, and data analysis techniques are explained.

In this study which aims to determine the intercultural sensitivity of Turkish as a foreign language teachers, the Single study model which is a Mixed Method Design Classification is used. Analysis of the data obtained from the research was made by using SPSS 21.00 statistical analysis program. It is considered that Turkish as a foreign language teachers have higher intercultural sensitivity perceptions $(-x=4.34)$. It can be said that teachers look positively to meet and interact with individuals from different cultures. "I think my culture is better than others" ( $\left.{ }^{-} x=3.36\right)$ has been identified as the lowest average medium item in the survey. The relationship between the gender variation and the factors like self-confidence in a cross-cultural interaction ( $t$ $(131)=1.54, p>.05)$, cross-cultural subjectivity $(t(131)=1.38, p>.05)$, cross-cultural interaction prejudice $(t$ $(131)=-0.49, p>.05)$ and care in cross-cultural interaction $(t(131)=-0.49, p>.05)$ were not statistically significant. There is a statistically significant relationship between gender variation and respect to the crosscultural differences $(\mathrm{t}(131)=2.83, \mathrm{p}<.05)$ within the framework of intercultural sensitivity of Turkish as a foreign language teachers. Between the factors as cross-cultural interaction participation $(t(131)=0.82, p>$ $.05)$, cross-cultural interaction subjectivity $(\mathrm{t}(131)=-0.29, \mathrm{p}>.05)$, cross-cultural interaction prejudice $(\mathrm{t}(131)=$ $-0.03, p>.05)$ and intercultural interaction care $(t(131)=-1.00 ; p>.05)$ and in-service training in the field of teaching Turkish as a Foreign Language were not statistically significant. Teachers participating in-service training seem to differ $\left({ }^{-} x=4.49\right)$ from the teachers who have not participated in-service training yet $\left({ }^{-} x=4.20\right)$ when the item "respect for intercultural differences" $(-x=4.49)$ is taken into account. In terms of the items that are respect to the cross-cultural differences $(t(131)=-0.12 ; p>.05)$, participation in cross-cultural interaction ( $t$ $(131)=1.38, p>.05)$, prejudice in cross-cultural interaction ( $t(131)=-0.13 ; p>.05)$, care in cross-cultural interaction $(t(131)=-1.00 ; p>.05)$ and the foreign language knowledge of the Turkish as a foreign language teachers that defines the factor about intercultural interaction sensitivity and the knowledge of foreign languages displayed that there is no statistically significant differences between them. In the research, 46 of the participating Turkish as a foreign language teachers stated that language and culture are integrated and both unique, 32 of those stated that cultural elements effect the teaching process positively in teaching Turkish as a foreign language; 29 of those stated that language teaching in teaching Turkish as a foreign language is a cultural transmission; 8 of those teachers stated that culture is important in terms of cultural interaction, 6 of the teachers stated that culture is important in terms of cultural values and 5 of them expressed that cultural education in teaching Turkish as a foreign language broadens the perspectives of individuals.

\section{Discussion, Conclusions and Recommendations}

At the end of the research, the findings showed that the Turkish as a foreign language teachers had a high cross-cultural sensitivity. As a result of the analysis applied in order to determine whether the opinions of teachers participating in the research differ or not when in-service training participation was taken into account, the findings showed that the Turkish as a foreign language teachers had higher levels of participation in cross-cultural interaction, subjectivity in cross-cultural interaction, prejudice in cross-cultural interaction, there was no statistically significant difference between the participants who received in-service training and those who did not. 